\section{RELATIONSHIP BETWEEN CARDIAC STRUCTURE AND FUNCTIONAL CAPACITY IN A FONTAN COHORT}

${ }^{1}$ Victoria Stoll*, ${ }^{2}$ Luke Pickup, ${ }^{2}$ Thomas Gaffey, ${ }^{1}$ Luke Rutter, ${ }^{1}$ Louis Luke, ${ }^{2}$ Sarah Bowater, ${ }^{2}$ Sara Thorne, ${ }^{2}$ Lucy Hudsmith, ${ }^{2}$ Paul Clift. ${ }^{1}$ University of Birmingham; ${ }^{2}$ University Hospitals Birmingham

10.1136/heartjnl-2017-311726.81

Introduction Follow up of Fontan patients involves a multimodality approach including imaging to assess cardiac function and cardiopulmonary exercise testing (CPET) to assess functional capacity. Decision making, including use of device therapy in conventional heart failure patients utilises predominantly structural information. We sought to assess whether cardiac structure as measured by conventional cardiac magnetic resonance parameters was related to functional capacity as assessed by CPET in a large Fontan cohort.

Methods 233 Fontan patients under follow up were identified. Of these 76 patients had undergone a CMR and CPET within 12 months. The cohort was divided into 2 groups 1) 47 patients with either a lateral tunnel or total cavo-pulmonary

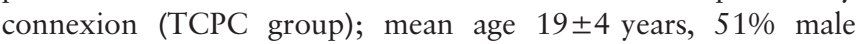
and 2) 29 patients with an atriopulmonary Fontan (AP group); age $29 \pm 7$ years, $48 \%$ male.

Results There were no significance differences in imaging parameters between the 2 groups. The peak $\mathrm{VO}_{2}$ was significantly higher in the TCPC group $(27 \pm 9 \mathrm{ml} / \mathrm{kg} / \mathrm{min})$ compared to the AP group $(22 \pm 8 \mathrm{ml} / \mathrm{kg} / \mathrm{min}, \mathrm{p} 0.009)$ (Table 1$)$. In the TCPC group only $19 \%$ of patients had a $\mathrm{EF}<55 \%$ whilst in the AP group this was $17 \%$. Predicted $\mathrm{VO}_{2}$ was reduced in both (TCPC $67 \pm 19 \%$, AP $62 \pm 18 \%$ ).

In the TPCP group the end diastolic volume (EDV), end systolic volume (ESV), stroke volume (SV) and ejection fraction (EF) did not correlate with the peak VO2, nor ventilatory product. Ventricular EF negatively correlated to NYHA class $(r=-0.41, p 0.005)$ as did ventricular mass $(r=-0.49, p$ 0.04). Rest partial pressure exhaled $\mathrm{CO}_{2}$ (rest $\mathrm{PETCO}_{2}$ ) correlated with the $\operatorname{EDV}(r=0.30, p$ 0.04) and SV $(r=0.32, p$ 0.03). In the AP group there was no correlation either between EDV, ESV, SV and EF with $\mathrm{VO}_{2}$ peak or ventilatory product. Rest $\mathrm{PETCO}_{2}$ correlated with EDV ( $\mathrm{r}=0.37$, p 0.04), whilst rest $\mathrm{O}_{2}$ pulse correlated with $\mathrm{SV}(\mathrm{r}=0.48, \mathrm{p} 0.009)$ and ventricular mass $(\mathrm{r}=0.53, \mathrm{p} 0.02)$.

When determined for each functional class in the TCPC group there was no difference in EDV (p 0.75). Ventricular EF was different between NYHA Class: NYHA I $(n=29)$ EF $64 \pm 8 \%$, NYHA II $(n=12) 55 \pm 7 \%$, NYHA III $(n=4) 63 \pm 7 \%$, NYHA IV $(\mathrm{n}=1) 51 \%$, P 0.005 , but this did not represent a stepwise decline. In the AP group for each functional class there was no difference in EDV ( $p$ 0.1) or EF ( $p$ 0.6). The peak $\mathrm{VO}_{2}$ was different between functional classes for the TCPC and AP groups. The TCPC results were NYHA Class I

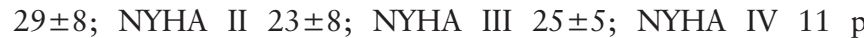
0.03, whilst those for the AP group are NYHA I 25 \pm 7 ; NYHA II 19 \pm 7 ; NYHA III 16 \pm 5 , (units $\mathrm{ml} / \mathrm{kg} / \mathrm{min}, \mathrm{p} \mathrm{0.006).}$ Discussion This study demonstrates that no conventional cardiac remodelling parameters related to the patients functional capacity. Fontan patients may be disadvantaged when assessed for advanced heart failure strategies as ventricular EF is a poor marker of functional capacity in this cohort and a study assessing response based on exercise parameters may be warranted.

\section{USE OF FEATURE TRACKING TO ASSESS SYSTEMIC RIGHT VENTRICLES IN CONGENITAL HEART DISEASE PATIENTS WITH BOTH SINGLE AND DUAL VENTRICULAR CIRCULATIONS}

${ }^{1}$ Victoria Stoll*, ${ }^{1}$ Boyang Liu, ${ }^{2}$ William Moody, ${ }^{2} J o h n$ Townend, ${ }^{2}$ Rick Steeds, ${ }^{1}$ Paulus Kirchhof, ${ }^{2}$ Paul Clift, ${ }^{2}$ Lucy Hudsmith. ${ }^{1}$ University of Birmingham; ${ }^{2}$ University Hospitals Birmingham

10.1136/heartjnl-2017-311726.82

Abstract 82 Table 1 Imaging parameters and exercise parameters for the TCPC Fontan group compared to the AP Fontan Group

\begin{tabular}{|c|c|c|c|}
\hline & $\begin{array}{c}\text { TCPC Fontan } \\
(n=47)\end{array}$ & $\begin{array}{l}\text { AP Fontan } \\
\text { ( } n=29)\end{array}$ & P value \\
\hline \multicolumn{4}{|c|}{ Imaging parameters } \\
\hline End diastolic volume, $\mathrm{ml}$ & $143 \pm 57$ & $132 \pm 58$ & 0.42 \\
\hline End systolic volume, $\mathrm{ml}$ & $56 \pm 28$ & $57 \pm 37$ & 0.93 \\
\hline Stroke volume, $\mathrm{ml}$ & $86 \pm 32$ & $75 \pm 29$ & 0.12 \\
\hline Ventricular mass, $\mathbf{g}$ & $88 \pm 24$ & $107 \pm 49$ & 0.13 \\
\hline Ejection fraction, \% & $61 \pm 8$ & $59 \pm 9$ & 0.21 \\
\hline \multicolumn{4}{|c|}{ Exercise parameters } \\
\hline Peak $\mathrm{VO}_{2}, \mathrm{ml} / \mathrm{kg} / \mathrm{min}$ & $27 \pm 9$ & $22 \pm 8$ & 0.009 \\
\hline Maximum workload, RER peak & $1.1 \pm 0.1$ & $1.1 \pm 0.1$ & 0.99 \\
\hline Ventilatory product $\mathrm{ml} /$ beat ${ }^{*} \mathrm{mmHg}$ & $324 \pm 170$ & $325 \pm 147$ & 0.99 \\
\hline VE/VCO ${ }_{2}$ slope & $34.5 \pm 5.7$ & $36.0 \pm 8.3$ & 0.36 \\
\hline
\end{tabular}

